\title{
HUBUNGAN ANTARA KARAKTERISKTIK PRIBADI, PERSEPSI, DAN DORONGAN DARI PIHAK LAIN TERHADAP MAHASISWA UNTUK MEMILIH JURUSAN AKUNTANSI DI POLITEKNIK NEGERI BATAM
}

\author{
Yulinda $^{1)}$ dan Afriyanti Hasanah ${ }^{2)}$ \\ 1), 2) Manajemen Bisnis, Politeknik Negeri Batam, Ahmad Yani, Batam Center, Batam 29461 \\ E-mail: ${ }^{1)}$ yulinda@polibatam.ac.id, ${ }^{2)}$ afriyantihasanah@polibatam.ac.id
}

\begin{abstract}
This research aimed to analyze the influence towards personal characteristic, preseption and encouragement from other parties towards to Students to select the majors in Accounting department in Politeknik Negeri Batam. This is supported by the number of students in choosing Accounting department in Politeknik Negeri Batam. Moreover, this study used primary data by taking data from Students in the first of semester from Accounting department. The results showed there is a relationship between personal characteristics and encouragement from other parties. Meanwhile, showed 1 hypothesis not supported in this study that there is no relationship perception of students to choose the department of Accounting in Politeknik Negeri Batam. Furthermore, this research can be an input for Politeknik Negeri Batam to see how much interest of student in choosing accounting majors and also for as input for in the future. Based on the study results, the conclusions and contribution for vocational education institutions, is important to improve the quality of applied Accounting department to be able to attract more students interest in choosing this department and to make qualified accounting graduates.
\end{abstract}

Keywords: personal characteristic, preseption, encouragement from other parties

\begin{abstract}
Abstrak
Penelitian ini bertujuan untuk meneliti Hubungan antara karakterisktik pribadi, persepsi, dan dorongan dari pihak lain terhadap mahasiswa untuk memilih jurusan Akuntansi di Politeknik Negeri Batam. Hal ini didukung oleh bahwa banyaknya jumlah mahasiswa dalam memilih Jurusan akuntansi di Politeknik Negeri Batam. Penelitian ini menggunakan data primer dengan mengambil data dari Mahasiswa semester awal dari jurusan Akuntansi di Politeknik Negeri Batam. Hasil penelitian menunjukkan terdapat hubungan antara karakteristik pribadi dan dorongan dari pihak lain. Sementara itu menunjukkan 1 hipotesis tidak terdukung dalam penelitian ini yaitu tidak terdapat hubungan presepsi terhadap mahasiswa untuk memilih jurusan Akuntansi di Politeknik Negeri Batam. Penelitian ini bisa menjadi masukan bagi Politeknik Negeri Batam untuk melihat seberapa besar minat mahasiswa dalam memilih jurusan akuntansi dan juga untuk sebagai masukan untuk di kedepan hari. Kesimpulan dan kontribusi hasil dari penelitian ini, bagi institusi pendidikan vokasi, penting untuk meningkatkan mutu jurusan Akuntansi terapan untuk dapat menarik lagi minat mahasiswa dalam memilih jurusan ini dan menjadikan lulusan akuntansi yang berkualitas.
\end{abstract}

Kata kunci: Karakteristik Pribadi, Presepsi, Dorongan dari Pihak lain 


\section{PENDAHULUAN}

Perguruan tinggi merupakan kelanjutan pendidikan bagi para lulusan Sekolah Menengah Atas dan Sekolah Menengah Kejuruan yang diselenggarakan untuk mempersiapkan peserta didik untuk menjadi anggota masyarakat yang memiliki kemampuan akademis dan profesional yang dapat menerapkan, mengembangkan dan menciptakan ilmu pengetahuan, teknologi dan kesenian (UU 2 tahun 1989, pasal 16, ayat:1). Dimana tujuan dari pendidikan lanjutan bagi para lulusan Sekolah Menengah Atas dan Sekolah Menengah Kejuruan ini adalah untuk mempersiapkan peserta didik untuk menjadi anggota masyarakat yang memiliki kemampuan akademis dan profesional yang dapat menerapkan, mengembangkan dan menciptakan ilmu pengetahuan, teknologi dan kesenian. Serta mengembangkan dan menyebar luaskan ilmu pengetahuan, teknologi, kesenian, dan serta mengoptimalkan penggunaannya untuk meningkatkan taraf hidup masyarakat dan memperkaya kebudayaan nasional (UU 2 tahun 1989, pasal 16, ayat:1).informasi yang transparan, organisasi yang akuntabel serta tata kelola perusahaan yang baik memaksa perusahaan untuk memberikan informasi mengenai aktifitas sosialnya (Anggraini, 2006).

Melihat rendahnya minat mahasiswa akuntansi untuk meningkatkan profesionalisme di tengah tingginya kebutuhan dan tuntutan peningkatan profesionalisme akuntan, penulis termotivasi untuk melakukan penulisan mengenai faktor-faktor yang mempengaruhi mahasiswa memilih prodi akuntansi sebagai prodi utama untuk melanjutkan jenjang karirnya di Politeknik Negeri Batam. Selain itu, penulisan ini juga termotivasi oleh penulisan-penulisan terdahulu mengenai faktor-faktor yang mempengaruhi mahasiswa memilih jurusan akuntansi.
Sebelumnya, Sugahara dan Boland (2009), dalam sebuah studi pada faktorfaktor yang mempengaruhi mahasiswa bisnis tersier Jepang pilihan pekerjaan, telah menyimpulkan bahwa karakteristik pribadi adalah pengaruh yang paling signifikan. Selain itu, dan jika dilihat dari penelusuran penelitian sebelumnya yang dilakukan oleh Felton et al (1994) menyatakan bahwa karakteristik pribadi didefinisikan sebagai faktor yang paling berkaitan dengan kepuasan inidividu untuk menjadi lebih kreatif di lingkungan kerja.

Penelitian ini merupakan penelitian pengembangan dari penelitian sebelumnya yang dilakukan oleh Lim Chhoung Tang Cheaseth (2016) mengenai faktor yang mempengaruhi keputusan siswa untuk memilih prodi akuntansi. Penelitian ini melakukan pengembangan dari beberapa penelitian terdahulu dengan menggabungkan beberapa variabel dari penelitian sebelumnya yang mungkin mempengaruhi minat mahasiswa dalam memilih prodi akuntansi. Penelitian ini dilakukan untuk meneliti kembali apakah penelitian sebelumnya konsisten dengan penelitian yang terjadi pada saat ini. Perbedaan penelitian sebelumnya dengan penelitian ini adalah : (1) penelitian ini dilakukan di Politeknik Negeri Batam, sedangkan penelitian sebelumnya dilakukan di empat Perguruan Tinggi di Kamboja. (2) penelitian ini menggunakan variabel atau indikator, yaitu karakteristik pribadi, persepsi, dan dorongan dari pihak lain sedangkan penelitian sebelumnya menggunakan variabel atau indikator bimbingan, harapan, persepsi, dan karakteristik pribadi.

\section{METODE PENELITIAN Desain Penelitian}

Jenis penelitian ini adalah penelitian kuantitatif, sedangkan menurut karakteristik masalahnya, penelitian ini termasuk dalam penelitian deskriptif yaitu penelitian terhadap masalah-masalah berupa fakta-fakta saat ini dari suatu 
populasi (Siregar, 2013: 33). Tujuan dari penelitian deskriptif adalah untuk menguji hipotesis atau menjawab pertanyaan yang berkaitan dengan current status dari subjek yang diteliti. Dalam penelitian ini, data primer diperoleh dengan metode survey melalui teknik pengumpulan data dengan kuesioner. Kuesioner didistribusikan secara langsung dengan diantar ke responden dan secara tidak langsung (melalui email kepada responden).

\section{Populasi dan Sampel}

Menurut Sugiyono (2009) populasi adalah wilayah generalisasi yang terdiri atas objek atau subjek yang mempunyai kualitas dan karakteristik tertentu yang ditetapkan oleh peneliti untuk dipelajari dan kemudian ditarik kesimpulannya. Populasi dalam penelitian ini adalah seluruh mahasiswa prodi akuntansi dan mahasiswa prodi akuntansi manajerial di Politeknik. Sampel adalah sebagian dari jumlah dan karakteristik yang dimiliki oleh populasi. Pengambilan sampel dalam penelitian ini dilakukan menggunakan pendapat Roscoe (2006), yang mana menurut Roscoe (2006) suatu sampel dikatakan baik jika berjumlah minimal 30 sampel dan maksimal 500 sampel untuk setiap kategori. Sampel dalam penelitian ini adalah mahasiswa jurusan akuntansi dan akuntansi manajerial di Politeknik Negeri Batam, jadi total keseluruhan sampel yang diambil dari mahasiswa prodi akuntansi dan prodi akuntansi manajerial di Politeknik Negeri Batam adalah minimal sebanyak 172 orang, minimal 80 orang dari mahasiswa prodi akuntansi dan minimal 70 orang dari mahasiswa prodi akuntansi manajerial.

\section{Jenis dan Sumber Data}

Jenis dan sumber data yang digunakan dalam penelitian ini menurut Sugiyono (2009) yaitu data primer. Dalam penelitian ini penulis menggunakan data primer dari hasil penyebaran kuesioner, yang diperoleh langsung dari responden yaitu mahasiswa prodi akuntansi dan akuntansi manajerial Politeknik Negeri Batam.

Teknik Teknik Pengujian Instrumen, Teknik Pengolahan Data, dan Teknik Analisis Data

Uji validitas digunakan untuk mengukur sah atau valid tidaknya suatu kuesioner. Suatu kuesioner dikatakan valid jika pertanyaan pada kuesioner mampu untuk mengungkapkan sesuatu yang akan diukur oleh kuesioner tersebut. Reliabilitas sebenarnya adalah alat untuk mengukur suatu kuesioner yang merupakan indikator dari variabel atau konstruk. Suatu kuesioner dikatakan reliabel atau handal jika jaawaban seseorang terhadap pertanyaan adalah konsisten atau stabil dari waktu ke waktu. Untuk mengukur konsistensi interval penggunaan instrumen digunakan Cronbach's Alpha Coefficient. Pada penelitian ini nilai Cronbach Alpha masing-masing variabel sama dengan atau lebih besar dari 0,6 yang berarti bahwa alat ukur dalam penelitian ini adalah reliabel atau handal. Data dalam penelitian ini diolah dengan tabulasi pada excel dan aplikasi SPSS 17.Teknik Analisis Data Analisis Tabulasi Silang (Crosstab). Pada prinsipnya menyajikan data dalam bentuk tabulasi yang meliputi baris dan kolom dan data untuk penyajian crosstab adalah data berskala nominal atau kategori. Chi-Square test digunakan untuk menguji apakah ada asosiasi atau hubungan antara faktor karakteristik pribadi, persepsi, dan dorongan dari pihak lain terhadap mahasiswa/i untuk memilih jurusan akuntansi di Politeknik Negeri Batam.

\section{HASIL DAN PEMBAHASAN Statistik Deskriptif}

Populasi dalam penelitian ini adalah seluruh mahasiswa prodi akuntansi dan mahasiswa prodi akuntansi manajerial di Politeknik Negeri Batam. Sampel dalam penelitian ini adalah mahasiswa jurusan 
akuntansi dan akuntansi manajerial di Politeknik Negeri Batam, jadi total keseluruhan sampel yang diambil dari mahasiswa prodi akuntansi dan prodi akuntansi manajerial di Politeknik Negeri Batam adalah minimal sebanyak 172 mahasiswa.

\section{Uji Validitas}

\begin{tabular}{|c|c|c|c|}
\hline KP & $\mathbf{r}$ hitung & $\mathbf{r}$ tabel & Keterangan \\
\hline 1 & 0.507 & 0.3 & valid \\
\hline 2 & 0.55 & 0.3 & valid \\
\hline 3 & 0.523 & 0.3 & valid \\
\hline 4 & 0.525 & 0.3 & valid \\
\hline 5 & 0.585 & 0.3 & valid \\
\hline 6 & 0.544 & 0.3 & valid \\
\hline 7 & 0.596 & 0.3 & valid \\
\hline 8 & 0.646 & 0.3 & valid \\
\hline 9 & 0.523 & 0.3 & valid \\
\hline 10 & 0.664 & 0.3 & valid \\
\hline 11 & 0.569 & 0.3 & valid \\
\hline 12 & 0.543 & 0.3 & valid \\
\hline 13 & 0.621 & 0.3 & valid \\
\hline
\end{tabular}

Dari tabel di atas terlihat bahwa angka r hitung untuk KP1 adalah sebesar 0,507, KP2 sebesar 0,550, KP3 sebesar 0,423, KP4 sebesar 0,125, KP5 sebesar 0,585, KP6 sebesar 0,244, KP7 sebesar 0,596, KP8 sebesar 0,646, KP9 sebesaar 0,523, KP10 sebesar 0,664, KP11 sebesar 0,069, KP12 sebesar 0,543, KP13 sebesar 0,621. Hasil tersebut menunjukkan bahwa pertanyaan no $1,2,3,4,5,6,7,8,9,10,11,12$, dan 13 adalah valid karena nilai $\mathrm{r}$ hitung lebih besar dari 0,3.

\begin{tabular}{|c|c|c|c|}
\hline$P$ & $r$ hitung & $r$ tabel & Keterangan \\
\hline 1 & 0.657 & 0.3 & Valid \\
\hline 2 & 0.493 & 0.3 & Valid \\
\hline 3 & 0.538 & 0.3 & Valid \\
\hline 4 & 0.628 & 0.3 & Valid \\
\hline 5 & 0.701 & 0.3 & Valid \\
\hline 6 & 0.614 & 0.3 & Valid \\
\hline 7 & 0.499 & 0.3 & Valid \\
\hline 8 & 0.598 & 0.3 & Valid \\
\hline 9 & 0.554 & 0.3 & Valid \\
\hline 10 & 0.623 & 0.3 & Valid \\
\hline 11 & 0.509 & 0.3 & Valid \\
\hline 12 & 0.649 & 0.3 & Valid \\
\hline
\end{tabular}

Dari tabel di atas terlihat bahwa angka $\mathrm{r}$ hitung untuk P1 adalah sebesar 0,657, P2 sebesar 0,493, P3 sebesar 0,538, P4 sebesar 0,628, P5 sebesar 0,701, P6 sebesar 0,614, P7 sebesar 0,499, P8 sebesar 0,598, P9 sebesaar 0,554, P10 sebesar 0,623, P11 sebesar 0,509, P12 sebesar 0,649. Hasil tersebut menunjukkan bahwa pertanyaan no 1 sampai 12 adalah valid karena nilai $r$ hitung lebih besar dari 0,3.

\begin{tabular}{|c|c|c|c|}
\hline DP & $\mathbf{r}$ hitung & $\mathbf{r}$ tabel & Keterangan \\
\hline 1 & 0.53 & 0.3 & valid \\
\hline 2 & 0.628 & 0.3 & valid \\
\hline 3 & 0.588 & 0.3 & valid \\
\hline 4 & 0.664 & 0.3 & valid \\
\hline 5 & 0.739 & 0.3 & valid \\
\hline 6 & 0.761 & 0.3 & valid \\
\hline 7 & 0.628 & 0.3 & valid \\
\hline 8 & 0.793 & 0.3 & valid \\
\hline 9 & 0.737 & 0.3 & valid \\
\hline 10 & 0.641 & 0.3 & valid \\
\hline 11 & 0.745 & 0.3 & valid \\
\hline 12 & 0.729 & 0.3 & valid \\
\hline
\end{tabular}

Dari tabel di atas terlihat bahwa angka r hitung untuk DP1 adalah sebesar 0,530, DP2 sebesar 0,628, DP3 sebesar 0,588, DP4 sebesar 0,664, DP5 sebesar 0,739, DP6 sebesar 0,761, DP7 sebesar 0,628, DP8 sebesar 0,793, DP9 sebesaar 0,737, DP10 sebesar 0,641, DP11 sebesar 0,745, DP12 sebesar 0729. Hasil tersebut menunjukkan bahwa pertanyaan no 1 sampai 12 adalah valid karena nilai $\mathrm{r}$ hitung lebih besar dari 0,3

\section{Uji Realibilitas}

\begin{tabular}{|c|c|c|}
\hline Cronbsch's Alphs & $\begin{array}{c}\text { Cronbach's Alpha Based on } \\
\text { Standardized Items }\end{array}$ & N of Items \\
\hline .804 & .813 & 10 \\
\hline
\end{tabular}

Tabel di atas menunjukkan bahwa nilai Cronbach Alpha 81,3\% yang menurut kriteria Nunnally (1994) bisa dikatakan reliabel.

\begin{tabular}{|c|c|c|}
\hline Cronbach's Alphas & $\begin{array}{c}\text { Cronbach's Alpha Based on } \\
\text { Standardizad Items }\end{array}$ & N of Items \\
\hline 824 & .830 & 12 \\
\hline
\end{tabular}

Tabel di atas menunjukkan bahwa nilai Cronbach Alpha 83\% yang menurut kriteria Nunnally (1994) bisa dikatakan reliable.

\begin{tabular}{|c|c|c|}
\hline Cronbsci'r's Alpha & $\begin{array}{c}\text { Cronbach's Alpha Based on } \\
\text { Standardizzd Items }\end{array}$ & N of Items \\
\hline .891 & .896 & 12 \\
\hline
\end{tabular}

Tabel di atas menunjukkan bahwa nilai Cronbach Alpha 89,6\% yang menurut kriteria Nunnally (1994) bisa dikatakan reliabel. 


\section{Pengujian Hipotesis}

Untuk melakukan pengujian hipotesis terdapat hubungan antara faktor karakteristik pribadi (x1), persepsi (x2), dan dorongan dari pihak lain (x3) terhadap mahasiswa/i untuk memilih jurusan di Politeknik Negeri Batam (y) digunakan uji Chi-Square.

\section{Hipotesis 1}

Hipotesis pertama yang diajukan dalam penelitian ini adalah terdapat hubungan antara karakteristik pribadi dan mahasiswa/i untuk memilih jurusan akuntansi di Politeknik Negeri Batam. Hipotesis ini terdukung apabila nilai Asymp.Sig < 0,05 atau Chi-Square hitung $>$ Chi-Square tabel dan hipotesis ini tidak terdukung jika nilai Asymp.Sig > 0,05 atau Chi-Square hitung < Chi-Square tabel.

\begin{tabular}{|l|r|r|rr|}
\hline & \multicolumn{1}{|c|}{ Value } & \multicolumn{1}{|c|}{ df } & \multicolumn{2}{|c|}{ Asymp. Sig. (2-sided) } \\
\hline Pearson Chi-Square & \multicolumn{1}{|c|}{18.357} & 26 & .046 \\
\hline Likelihood Ratio & 22.386 & 26 & .667 \\
\hline $\begin{array}{l}\text { Linear-by-Linear } \\
\text { Association }\end{array}$ & 2.208 & 1 & .137 \\
\hline N of Valid Cases & 172 & & & \\
\hline
\end{tabular}

Chi-Square test digunakan untuk menguji apakah ada asosiasi atau hubungan antara faktor karakteristik pribadi dan mahasiswa/i untuk memilih jurusan akuntansi di Politeknik Negeri Batam. Hasil Chi-Square menunjukkan nilai sebesar 18.357 dengan probabilitas signifikansi 0,046. Chi-Square hitung < Chi-Square tabel $(18.357<38,89)$, dan nilai signifikansi di bawah 0,05, Artinya ada hubungan atau assosiasi antara faktor karakteristik pribadi dan mahasiswa/i untuk memilih jurusan akuntansi di Politeknik Negeri Batam. Maka dapat disimpulkan bahwa H1 terdukung atau diterima.

\section{Hipotesis 2}

Hipotesis kedua yang diajukan dalam penelitian ini adalah terdapat hubungan antara persepsi dan mahasiswa/i untuk memilih jurusan akuntansi di Politeknik Negeri Batam. Hipotesis ini terdukung apabila nilai Asymp.Sig < 0,05 atau ChiSquare hitung $>$ Chi-Square tabel dan hipotesis ini tidak terdukung jika nilai Asymp.Sig $>0,05$ atau Chi-Square hitung $<$ Chi-Square tabel.

\begin{tabular}{|l|r|r|rr|}
\hline & \multicolumn{1}{|c|}{ Value } & \multicolumn{1}{|c|}{$\mathrm{df}$} & \multicolumn{1}{|c|}{ Asymp. Sig. (2-sided) } \\
\hline Pearson Chi-Square & 34.884 & 24 & .070 \\
\hline Likelihood Ratio & 37.875 & 24 & .036 \\
\hline $\begin{array}{l}\text { Linear-by-Linear } \\
\text { Association }\end{array}$ & .460 & 1 & .498 \\
\hline N of Valid Cases & 172 & & & \\
\hline
\end{tabular}

Chi-Square test digunakan untuk menguji apakah ada asosiasi atau hubungan antara faktor persepsi dan mahasiswa/i untuk memilih jurusan akuntansi di Politeknik Negeri Batam. Hasil Chi-Square menunjukkan nilai sebesar 34.884 dengan probabilitas signifikansi 0,070. ChiSquare hitung < Chi-Square tabel (34.884 $<36.42$ ), dan nilai signifikansi di atas 0,05 , Artinya tidak ada hubungan atau assosiasi antara faktor persepsi dan mahasiswa/i untuk memilih jurusan akuntansi di Politeknik Negeri Batam. Maka dapat disimpulkan bahwa $\mathrm{H} 2$ tidak terdukung atau ditolak.

\section{Hipotesis 3}

Hipotesis ketiga yang diajukan dalam penelitian ini adalah terdapat hubungan antara dorongan dari pihak lain dan mahasiswa/i untuk memilih jurusan akuntansi di Politeknik Negeri Batam. Hipotesis ini terdukung apabila nilai Asymp.Sig < 0,05 atau Chi-Square hitung $>$ Chi-Square tabel dan hipotesis ini tidak terdukung jika nilai Asymp.Sig $>0,05$ atau Chi-Square hitung <.Chi square table.

\begin{tabular}{|l|r|r|r|}
\hline & \multicolumn{1}{|c|}{ Value } & \multicolumn{1}{|c|}{$\mathrm{df}$} & Asymp. Sig. (2-sided) \\
\hline Pearson Chi-Square & $45.197^{2}$ & 37 & .047 \\
\hline Likelihood Ratio & 42.723 & 37 & .239 \\
\hline Linear-by-Linear & .046 & 1 & .831 \\
Association & & & \\
\hline N of Valid Cases & 172 & & \\
\hline
\end{tabular}

Chi-Square test digunakan untuk menguji apakah ada asosiasi atau hubungan antara faktor dorongan dari pihak lain dan mahasiswa/i untuk memilih jurusan akuntansi di Politeknik Negeri Batam. Hasil Chi-Square menunjukkan nilai sebesar 45.197 dengan probabilitas signifikansi 0,047. Nilai signifikansi di bawah 0,05, Artinya ada hubungan antara faktor dorongan dari pihak lain dan mahasiswa/i untuk memilih jurusan 
akuntansi di Politeknik Negeri Batam. Maka dapat disimpulkan bahwa H3 terdukung atau diterima.

\section{Analisis Data}

Berdasarkan hasil dari uji Chi-Square maka ringkasan hasil pengujian hipotesis dapat dilihat pada tabel 4.11 dibawah ini:

\begin{tabular}{|c|l|c|c|}
\hline \multicolumn{2}{|c|}{ Hipotesis } & Sig. & Kesimpulan \\
\hline H1 & $\begin{array}{l}\text { Terdapat hubungan antara karakteristik } \\
\text { pribadi dan mahasiswa i untuk memilih } \\
\text { jurusan akuntansi di Politeknik Negeri } \\
\text { Batam }\end{array}$ & 0,046 & Terdukung \\
\hline H2 & $\begin{array}{l}\text { Terdapat hubungan antara persepsi dan } \\
\text { mahasiswa/ inntuk memilih jurusan } \\
\text { akuntansi di Politeknik Negeri Batam }\end{array}$ & 0,070 & Tidak terdukung \\
\hline H3 & $\begin{array}{l}\text { Terdapat hubungan antara dorongan dari } \\
\text { pihak lain dan mahasiswa/i intuk memilth } \\
\text { jurusan akuntansi di Politeknik Negeri } \\
\text { Batam }\end{array}$ & 0,047 & Terdukung \\
\hline
\end{tabular}

Hubungan antara karakteristik pribadi dan mahasiswa/i untuk memilih jurusan akuntansi di Politeknik Negeri Batam

Berdasarkan Uji Chi-Square, H1 menunjukkan terdapat hubungan antara karakteristik pribadi dan mahasiswa/i untuk memilih jurusan akuntansi di Politeknik Negeri Batam. Hal ini menunjukkan bahwa hipotesis pertama (H1) terdukung. Penelitian ini sejalan dengan penelitian yang dilakukan oleh Martini (2013) yang menunjukkan bahwa faktor pribadi tidak berpengaruh terhadap pemilihan jurusan akuntansi. Penelitian ii juga sejalan dengan penelitian yang dilakukan oleh Irmawati (2008). Hal ini diduga karena mahassiswa terpaksa menggambil prodi yang bukan dari keinginan dirinya sendiri, mahasiswa hanya ikut-ikutan teman sebaya atau hanya formalitas yang ingin menunjukkan bahwa dirinya sebagai mahasiswa.

Hubungan antara persepsi dan mahasiswa/i untuk memilih jurusan akuntansi di Politeknik Negeri Batam

Berdasarkan Uji Chi-Square, H2 menunjukkan tidak terdapat hubungan antara persepsi dan mahasiswa/i untuk memilih jurusan akuntansi di Politeknik Negeri Batam. Hal ini menunjukkan bahwa hipotesis kedua (H2) tidak terdukung. Hasil penelitian ini sejalan dengan penelitian yang dilakukan oleh Surjawati dan Widowati (2015) yang menunjukkan bahwa persepsi akuntansi selalu dibutuhkan dalam bisnis merupakan faktor utama para responden memilih jurusan akuntansi.

Hubungan antara dorongan dari pihak lain dan mahasiswa/i untuk memilih jurusan akuntansi di Politeknik Negeri Batam

Berdasarkan Uji Chi-Square, H3 menunjukkan terdapat hubungan antara dorongan dari pihak lain dan mahasiswa/i untuk memilih jurusan akuntansi di Politeknik Negeri Batam. Hal ini menunjukkan bahwa hipotesis ketiga (H3) terdukung. Hasil penelitian ini sejalan dengan penelitian yang dilakukan oleh Fitria (2013) yang menunjukkan bahwa faktor lingkungan tidak berpengaruh signifikan terhadap minat memilih perguruan tinggi. Indicator dari faktor lingkungan adalah dukungan dari orang tua, keluarga/ kerabat dekat, teman, dan lingkungan masyarakat.

\section{KESIMPULAN DAN SARAN}

Penelitian ini menguji apakah terdapat Hubungan antara karakteristik pribadi, persepsi, dan dorongan dari pihak lain terhadap mahasiswa/i untuk memilih jurusan akuntansi di Politeknik Negeri Batam. Sampel dalam penelitian ini adalah mahasiswa prodi akuntansi dan akuntansi manajerial di Politeknik Negeri Batam. Jumlah sampel adalah 172 mahasiswa. Berikut adalah kesimpulan yang dapat diambil dari penelitian ini:

a. Berdasarkan Uji Chi-Square diperoleh bahwa terdapat hubungan antara karakteristik pribadi dan mahasiswa/i untuk memilih jurusan akuntansi di Politeknik Negeri Batam

b. Berdasarkan Uji Chi-Square diperoleh bahwa tidak terdapat hubungan antara persepsi dan mahasiswa/i untuk memilih jurusan akuntansi di Politeknik Negeri Batam. 
c. Berdasarkan Uji Chi-Square diperoleh bahwa terdapat hubungan antara dorongan dari pihak lain dan mahasiswa/i untuk memilih jurusan akuntansi di Politeknik Negeri Batam.

\section{DAFTAR PUSTAKA}

Auyeung \&Sands (1997). Faktor-faktor yang mempengaruhi pilihan mahasiswa akuntansi

Andriani, \& Adam (2013). Pengaruh Biaya Pendidikan, Latar Belakang Sosial Ekonomi, Motivasi,dan Reputasi Terhadap Minat Mahasiswa Dalam Memilih Prodi S1 Akuntansi Perguruan Tinggi di Malang.

Diponegoro. Semarang Gibson and Donely. 1994. The Official Publication of the Association of

Fitria, Hadiyati (2013). Faktor-faktor yang mempengaruhi minat mahasiswa memilih perguruan tinggi ekonomi islam. Jurnal ekonomi dan perbankan Syariah

Fitria, Nur (2016). Persepsi dan minat mahassiswa jurusan akuntansi fakultas ekonomi terhadap profesi akuntan public

Ghozali, Imam. 2006. Aplikasi Analisis Multivariet dengan Program SPSS. Badan Penerbit Universitas

Hadibroto. 1997. CPA Accountibility Media Akuntansi Edisi 11/ Juli/VII/ hal. 16.

Irmawati, Basilia Ria (2008). Faktorfaktor yang mempengaruhi mahasiswa dalam memilih program studi di perguruan tinggi

Kuningsih, R. S. (2013). Faktor-Faktor yang Mempengaruhi Niat Mahasiswa untuk Berkarir. Semarang: Universitas Diponegoro.

Lestari. 2013, Persepsi dan Minat Mahasiswa Jurusan Akuntansi

Malgwi, Howe, \& Burnaby (2005). Pengaruh siswa memilih perguruan tinggi
Martini (2013). Analisa Faktor-faktor yang mempengaruhi pemilihan jurusan akuntansi sebagai tempat kuliah di perguruan tinggi

Physical Plants Administrator of Universitas and Colleges. USA: Association.

Saeman \& Crooker (1999). Faktor-faktor yang mempengaruhi pilihan siswa akuntansi.

Surjawati \& Widowati (2015). Studi tentang keputusan memilih jurusan S1 akuntansi

Syamsi, (2000), Pengambilan keputusan berdasarkan wewenang juga memiliki beberapa kelebihan dan kelemahan.

Tan \& Fawzi (2006). Sikap, niat, dan keyakinan siswa untuk memilih jurusan akuntansi 
